\title{
Del sexo a la rosa: Erotismo en la poesía de Clementina Suárez
}

Claudia S. Torres*

Ya pesar del miedo estoy tranquila. Llena de

de sonidos y llantos, de dolores en las piernas

recorrido los mil mercados de Tebas, de recuerdos

que me hicieron reír con sus historias de monstruosy

"Los ángeles que pasean pormi sangre son ángeles rebeldes

(Clementina Suárez)

Jamás pensé que un día analizaría la poesía de Clementina Suárez, ni que me sentiría identificada con sus espacios de belleza y libertad. Me duele imaginar su muerte; sin embargo, estoy segura de que esté donde esté andará con sus boas estelares regando caricias y cambiando a quienes la rodean. Clementina era gestora de almas, con lo bueno y con lo malo que eso implica.

En su obra poética, Clementina Suárez nos presenta un erotismo liberador que se construye a través de una exploración de las maneras con las cuales uno ama al "otro/a", al extraño, a lo desconocido, y a lo-que-no-soy-para-nada; a su vez, esta no-apropiación está ligada a una relación transgresora de la Ley Moral. (Cixous citada por Shiach 1991). Existen otras formas de experimentar el mundo, de generar conocimientos que no se acomodan a una racionalidad académica, sino que buscan "la verdad en la medula de (los) huesos" (Suárez citada por Ramos 1982). Son las personas que no tienen miedo de enfrentarse a la existencia propia de las cosas, de confrontar su propia materialidad, de reflexionar sobre su mundo interior, de abrazar su sombra, de morder la manzana. (ibid). Esta manera de generar conocimiento no acepta el poder abstracto y simbólico de la Ley, se opone a las prohibiciones. Se evidencia a un rechazo a internalizar las estructuras represivas de un sistema y se caracteriza por una apertura a todo, a una genuina autenticidad, a las múltiples posibilidades del inexperto (Suzuki), al deseo de habitar nuestros cuerpos sin limitarnos únicamente a lo oculocéntrico, característico de la Cultura Occidental (Shohat 1994).

Para recrear esa prolongada búsqueda que parte de lo sensual hacia mayores

${ }^{*}$ Claudia S. Torres

Escuela de Letras, Universidad Nacional Autónoma de Honduras 
niveles de dignidad y espiritualidad, escogí la imagen del sexo a la rosa. El sexo carnal puede convertirse en una intimidad profunda que permita conocer los miedos para desatarlos y transformarlos en rosa con aroma, espinas y belleza (poesía).Carlos Izaguirre nos dice que Clementina "se debate en el esfuerzo supremo de remontarse a las altas regiones de la serenidad y del silencio" (1982). Hostilio Lobo dice "padece la obsesión de la sangre trasmutada en alma" (1982). Claudia Lars expresa que la poesía de Clementina "es el grito de la sangre libre y del espíritu sin cadenas, de la personalidad que se afirma en algo más alto" (1982). Francisco Salvador, elocuentemente plantea "la grandeza de su alma se desborda en expansión, contra todo lo que es estrecho y no reconoce ni límite ni espacio ni de prejuicio" (1982). Clementina misma presenta su preocupación por "romper esta cáscara y alcanzar la espiritualidad" (1982 ) A través de las experiencias eróticoamorosas establece una cosmovisión en la cual el "vibrante goce sensual, en impulso o realización, está siempre presente" (Umaña 1986:217). La vida y obra de Clementina Suárez, según Rigoberto Paredes "se erigen, por tanto, en hitos precursores de una forma de hacer, de una manera de ser iconoclastas, eclosivas, sin duda necesarias para potenciar todo proceso de transformación material y espiritual" (Paredes citado por Ramos 2002). Medardo Mejía señala que Clementina "ha ido contra sí misma en el vértigo de la purificación" (1982).

Obediente la rosa a su destino

Tuvo que ir mostrando

El candor de su rostro.

Te quemará el amor tus huesos.

¡ Niña del aire!

¡Paloma del amanecer!

Ya que sólo en la sangre despierta

Estará el germen creador defendido.

No caerá poreso

La estrella de tumano.

Ligaduras humanas no detienen

Tu rostro, ya salvado en mil edades.

Ningún camino aparta al cielo de su cielo.

Todo te alza a la altura de tu llaga.

Conmigo. Contigo. Sola.

Atada va la sangre

Araíces que no entiende 
(Creciendo con la hierba)

Erotismo, según el Diccionario Larousse, significa carácter de erótico (455) y erótico es relativo al amor, especialmente al sexual. El erotismo es el resultado de una construcción social, cultural e individual que se dimensiona gradualmente según las experiencias, los valores y la estética. Aprendemos a habitar nuestro espacio sensual y sexual. Esta construcción parte de los sentidos y es influenciada por los valores culturales y las vivencias. Se va generando a partir de las experiencias sensuales, sexuales y cognitivas. Nuestras preferencias en el juego del amor varían infinitamente. El tipo de atracción que seduce a un camionero no es igual a la seducción de un intelectual, aunque existen excepciones a la regla.

Oller y D' Amico hablan de la importancia de las competencias semióticas y las relaciona con diferentes sistemas de comunicación: simbólico, cinestésico y lingüístico. Estos tres se apoyan el uno al otro y se retroalimentan. Bourdieu habla de un capital semiótico sostenido por estructuras que condicionan un habitar y un desplazar del cuerpo (habitus y hexis) (1994). Estos constructos se arman poco a poco con las experiencias de la vida, espacio interior y espacio exterior. "Para conocerse a sí mismos, se necesita salir de lo interior, y relacionarse con lo exterior $y$, así, enfrentarse con el otro y la negatividad. Pero, esto todo sirve para volver a sí mismos, y reconocerse mejor". (Bonagura 1991: 16)

Ya ves como

Mipecho ilumina

Una verdad tremenda.

Los ángeles que pasan por mi sangre

Son ángeles rebeldes.

Yme humillatu rostro atado

Ytu corazón cerrado

Porun mandato de siervos.

Cuando yo oíme dijeron:

Pequeña: No le niegues al amor tu cara.

Sólo asi tu flor tendrá polen

Y flotara libre, goteando muchedumbres, tu cara creciendo con la hierba. 
Distintos son los rumbos de la carne

Y sólo el viento salvará

Atu pie, que en la ceniza

Quedo extraviado...

(Creciendo con la hierba)

Sartre indica que la primera gran revolución es la mental. Señala que existe un proceso dual necesario para la acción, la externalización del mundo interior y la internalización del mundo exterior. Ambos procesos son necesarios para la acción ya que ésta es una confrontación entre el sujeto y el mundo. En un sentido amplio, la conciencia revolucionaria es una conversión de la conciencia producida por una variación imaginaria; es el poder de crear nuevos significados en el presente, creando un futuro revolucionario que lo niega (Sartre citado por Bourdieu 1992).

Este poder de crear nuevos significados en el presente implica invertir el mundo oficial (statu quo) para imaginarlo de otra manera, como lo deseamos 0 desearíamos. Esa visión a futuro es el poder que cambia las leyes actuales (vacías) por unas de nuevo contenido. Clementina pide al "pobre hombre" que juzga que la comprenda, que ella no tiene miedo de lo que cuerpo y alma le piden.

Poreso soy inquieta como pira;

poreso soy vibrante como una lira.

Comprende, comprende, Pobre hombrequejuzgas

Conforme a tus leyes humanas.

(Compréndeme)

Clementina percibe ese sentir de su cuerpo como algo más real que las leyes humanas. Para ella son leyes vacías que detienen ese fluir del vivir, esa inquietud que quema, ese sentir que vibra con la belleza de la lira. Se da cuenta que él está, como muchos, atrapados en las leyes humanas que reprimen la humanidad de los seres. Ella deja que el amor, el placer enciendan todo su cuerpo y su alma.
Yelbesoluminoso, o el beso tembloroso, o el beso impreciso, o el beso angustiado enciende micarne, 
enciende mis nervios, enciende mis huesos, enciende mi alma.

(Compréndeme)

Los estudios de Foucault tratan de desmitificar el significado cultural del sexo (o su reificación) y explican que existe una inmensa verbosidad organizada alrededor del sexo, la cual resulta necesaria para nuestra civilización y sus esquemas represivos. Se trata de un discurso sobre el placer y el autor sentencia que en un futuro la gente no podrá entender como el uso de la sexualidad y del poder que sostiene la organización de la misma fueron capaces de mantener la sujeción a una austera monarquía del sexo (citado por Stanton 1990:1). Para Sedgwick, el sexo es la actividad humana más significativa (1992:2) y para Gould no se puede reducir la importancia del sexo a "una señal, un símbolo o reflexión de absolutamente todo en nuestra cultura" (ibid.). Marcuse acusa que la represión sexual es un acto de cruel dominación. Accad previene que a menos que se incorpore una revolución sexual en la revolución política, no habrá una transformación real en las relaciones sociales (ibid).

\author{
¡ Criatura de miamor! \\ Sólo cuando el fuego \\ te lleve hasta mi grito \\ recuperarás intacta \\ la espiga que dentro \\ de tu piel madura.
}

Fuera necesario morirme y no quererte.

Golpearme la espalda

Yatarmi lengua

para no decirte

que están llorando en tí los brotes

y detenidos los arroyos,

porque le niegas al surco

lo que es del surco.

(Creciendo con la hierba)

El debate sobre esta revolución sexual tiene décadas de irrumpir en muchas reuniones, sesiones y conversatorios; no hay una única respuesta. La reflexión 
sobre estos temas parte de los valores sociales perpetuados a través de las mitologías de opresión que sobreviven y que sustentan la represión internalizada que asegura el statu quo. La subalteridad silencia el derecho a su propia sensualidad, a su deseo, a su imaginario; y por ello surgen esas resistencias subterráneas que si se urgan mucho salen como chorros de agua (Semeretakis 1996). El mundo se interpreta de manera falocéntrica y hasta en la arquitectura nos muestran orgullosas torres gigantescas. La mujer que reclama derechos es una igualada y se reprime con gran fuerza social.

\title{
Es crimen hablar de estrellas cuando hay que limarcadenas.
}

Medardo Mejía dice que después de publicar esos versos, "bramó el feudalismo, casi estuvo a punto de enterrarla viva," pero ella contesto:

\author{
No, no, no \\ Este no es mimar, \\ Niestos son mis ojos. \\ En estas aguas los niños están muertos \\ Y los vientres de madre comidos de gusano.
}

Para Cixous, la exploración de la subjetividad y de la sexualidad permite el desarrollo de alternativas textuales, políticas y económicas que se describen femeninas. La importancia de la búsqueda de la propia voz, la importancia de la levedad, del vuelo y de la necesidad de combinar técnicas deconstructivas y reconstructivas en la escritura. (Schiach 1991).

La escritura de Clementina es una búsqueda de significados, deconstruye y reconstruye a su manera. Descubre que su vida era "resplandor de lo bello y que podía hacer de ella una obra de arte" (Mejía 1982:7), agregaría yo, y de rebeldía. Se reescribió cantando libremente en un contexto de cadenas:

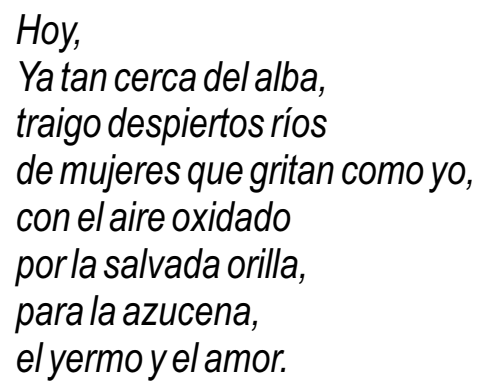




\title{
(Creciendo con la hierba)
}

Clementina entendió que esa transformación integral de los seres humanos era necesaria para la transformación social. A pesar de todas las contradicciones (el ser humano no es monolítico), opinaba que "El entendimiento entre hombre y mujer avanzará poco, mientras no se llegue a un plano de compañerismo (que vivió con su padre, en sus múltiples amores sin encontrarlo). Se casó dos veces y amo y fue amada.

\author{
Sólo así, \\ Aorillas de la vida \\ que buscajubilosa \\ algo duradero.
}

\section{Empezaremos \\ a serfelices, \\ a quererlo ser.}

\section{Asumiendo el deber}

De que sólo

Porun camino humano

Se puede serfeliz.

\author{
Sin lo estéril \\ de la desigual, \\ solitaria felicidad.
}

(Creciendo con la hierba)

Un día cuando le conté que me iba a divorciar me dijo, "las mujeres inteligentes como vos, se quedan solas. No les aguantan a los hombres pencos". Luego, agregó con satisfacción, "la vida es un entrenamiento en soledad". Pienso que se refería a una soledad especial esa que no comparte los niveles más íntimos. Clementina se sentía a gusto con su propia compañía y con su espacio, cuidadosamente recreado en su casa llena de sus retratos, de sus libros, de sus plantas y de su colección de objetos artesanales traídos de todas partes del mundo. Varias salas y una cocina chiquita. Su casa era el centro de reunión de muchos escritores y artistas.

Ahora,

a cualquierlugarque llegue 
ya nunca puedo estar sola, porque no comienzo en la sangre de mis descendientes sino que termino en ella.

(Con mis versos saludo a las generaciones futuras)

Su revolución sexual fue una búsqueda de sí misma y de sus anhelos. Era una mujer que buscaba que la trataran de igual a igual y el costo fue enorme. Mejía dice,

de casa rica vino Clementina Suárez. De casa feudal con amplias salas y amplios corredores, asentada en fértil valle. De casa de latifundistas y ganaderos, que en América Hispana han dirigido la Sociedad y han sido dueños de la cultura. A Clementina Suárez no le gustó el señorío, el hábito severo, el gesto desdeñoso, el tratamiento de "ama". Escapó del fértil valle natal. Quería cantar libremente y lo consiguió (1982:9)

Según Francisco Salvador, Clementina "se libera de medidas y condiciones para alimentar la libertad íntima, el amor permanente, el gozo del gozo, la razón social" (1982:87). "No sabe de cenáculos, de reglas, ni de academias. Todo en ella es elástico, impulso, ímpetu de libertad" (89). Orantes señala que "Clementina Suárez que es el sexo hecho verbo, habla por el espíritu y para el espíritu" (1982:15). Ella misma en una entrevista de José Muños Cota en la que le pregunta sobre el amor libre dice,

No hay tal, Soy partidaria del amor. En el matrimonio o fuera del matrimonio. Eso es cuestión de circunstancia eventuales. Lo que sí es cierto es que no creo en familiares, ni en deberes, ni en obstáculos. Me doy el lujo de escogerlos en el amplio escenario de la vida. Opinar ¿para qué? (1982:69).

Clementina no acepta el poder abstracto y simbólico de la ley, se opone a las prohibiciones. Se evidencia en su rechazo a la internalización de las estructuras represivas del sistema y a propugnar la fuerza vibrante de la vida natural del planeta que nos vuelve libres:

Supecho estuvo cierto

Enla evidencia

de que no hay otra vida sino aquella

que por el camino de la sangre

hacemosnuestra. 
Porque sólo el hombre oprimido, ahogado de noche o de terror alcanzará la apropiada medida para revivir en forma exacta la desfallecida corteza delplaneta.

Sus manos frescas trabajan con redoblado afán, sin reposo, para que renazca encendida - levantada en raícesla verdad de ser libres.

(Elegía de la sangre heroíca)

Y se caracteriza por una apertura a todo, a una genuina autenticidad, a las múltiples posibilidades del inexperto, al deseo de habitar nuestros cuerpos sin limitarnos únicamente a lo oculocéntrico:
ElArcano ha querido
que florifique al Mundo, riente como rosa en la cruz del beso.
Lo frívolo mío es el ardormirífico de los cuatro Puntos, es el gemido lírico delfuego, delagua, del viento y la tierra, boas estelares que me vuelven mítica.

Su cuerpo es el universo, es su templo, es su casa y lo habita como Scherezada que lo sabe todo, posee una cosmovisión en la cual el "vibrante goce sensual, en impulso o realización, está siempre presente" (Umaña 1986217):

Animal sidéreo

bello amado mío, 
hunde tus esplines

entre mis jazmines,

Yo soy Scherezada

Quelo sabe todo,

Tú el rey tremendo

Que no sabe nada.

Miespiritu es llave

que abre todas las puertas,

que abre todas las cajas

milagrosas que guardan

el perfume de las estrellas

y las gemas de los soles,

todas las cosas bellas.

Misabiduría

Es la fragancia

de la rosa de mi ignorancia.

Miciencia

Es la ciencia del lirio:

vivir,

perfumar,

lucir,

amar

las piedras, las aves,

el cielo azul,

nido magnífico

de las pálidas constelaciones miríficas.

(Explicaciones)

En su obra poética, Clementina Suárez nos presenta un erotismo liberador, del sexo a la rosa, que se construye a través de una exploración de las maneras con las cuales uno ama al "otro/a", al extraño, a lo desconocido, y a lo-que-no-soy-paranada. Y, a su vez, esta no- apropiación está ligada a una relación transgresora de la Ley de los hombres. (repetido en el segundo párrafo) Existen otras formas de experimentar el mundo, de generar conocimientos que no se acomodan a una racionalidad académica sino que buscan "la verdad en la medula de (los) huesos" y Clementina la buscó en sus huesos y en su sensualidad, sexualidad y espiritualidad panteísta. 
Sexo,

encarnada rosa,

florde lujuria

pordonde salta mijuventud.

Anfora llena

de sensaciones

y vibraciones.

Arpa que vibra, que llora y gime voluptuosidades.

Pero yo te bendigo

gruta maravillosa

porque la vida me diste

y porque en esa flor estropeada

una nueva vida

yo también di. . .

(Sexo) 